\title{
Impact of leaks in sulfur hexafluoride and nitrogen multiple-breath washout
} \section{systems}

\section{To the Editor:}

A recent study by LENHERR et al. [1] helps quantify impacts of leaks on multiple-breath washout (MBW) systems for functional residual capacity (FRC) and lung clearance index (LCI) measurements. In my view, technical leaks (post-capillary and intra-capillary leaks) are avoidable by careful testing of the equipment before connecting to the patient. However, pre-capillary leaks (interface between the device and patient) will occur, even in carefully controlled tests. The study [1], based primarily on computer modelling, provides detailed data showing that LCI measurements are relatively insensitive to expiratory leaks, but quantitative data on errors due to inspiratory leaks are not reported. It is, however, important to note that inspiratory leaks have a much higher impact on nitrogen $\left(\mathrm{N}_{2}\right)$ MBW LCI and FRC measurements than expiratory leaks.

The study is relevant for a specific $\mathrm{N}_{2}$ MBW system, but the authors mention that sulfur hexafluoride $\left(\mathrm{SF}_{6}\right) \mathrm{MBW}$ measurements are prone to similar leaks. This is correct, but the impact of inspiratory leaks in $\mathrm{SF}_{6} \mathrm{MBW}$ systems is entirely different because $\mathrm{SF}_{6}$ is washed out with air. Therefore, an inspiratory leak does not affect the $\mathrm{SF}_{6}$ concentration but only inspiratory flow, which is not used to calculate FRC or LCI. Consequently, the $\mathrm{SF}_{6} \mathrm{MBW}$ method is insensitive to inspiratory leaks.

For $\mathrm{N}_{2} \mathrm{MBW}$ systems, even a small inspiratory leak causes an error in the $\mathrm{N}_{2}$ washout curve with a substantial change in the LCI point. As an example, a continuous leak of only $1 \%$ with an alveolar ventilation of $6 \mathrm{~L} \cdot \mathrm{min}^{-1}\left(100 \mathrm{~mL} \cdot \mathrm{s}^{-1}\right)$ causes a nitrogen leak flow into the lungs of $0.8 \mathrm{~mL} \cdot \mathrm{s}^{-1}$, which moves the $\mathrm{N}_{2}$ concentration at the LCI point by $0.8 \%$, corresponding to $40 \%$ (relative) of the concentration at the LCI point without a leak. A leak of this size is not easily spotted, but it causes an error of the same order of magnitude as the error caused by $\mathrm{N}_{2}$ back diffusion [2], which has been shown to affect the LCI point significantly, changing it from $1 / 40$ of the initial $\mathrm{N}_{2}$ concentration to, on average, around $1 / 60$ of the initial concentration. The impact on the LCI point of an isolated leak in a few respirations is not predictable as it depends on both timing and level of ventilation heterogeneity. However, the relative error in calculated FRC equals the ratio between the volume of the leak and true FRC. The consequence of an inspiratory leak in an $\mathrm{N}_{2} \mathrm{MBW}$ system is to abort the test and perform the $\mathrm{N}_{2}$ wash-in procedure before restart of the test, increasing test duration.

Expiratory leaks affect LCI and FRC measurements by $\mathrm{N}_{2}$ and $\mathrm{SF}_{6} \mathrm{MBW}$ systems similarly. Inspiratory leaks affect the wash-in phase of $\mathrm{SF}_{6} \mathrm{MBW}$ systems. For open-circuit $\mathrm{SF}_{6}$ wash-in [3], the leak is easily detected by the failure to obtain complete equilibration during wash-in. In the closed-circuit wash-in system [4], an inspiratory leak is also easily detected as a transient dip in $\mathrm{SF}_{6}$ concentration during inspiration. In both cases, it is possible to ensure a leak-free system before the washout by adjusting patient interface (nose clip, mouthpiece or face mask) with limited increase in test duration.

\section{Jørgen G. Nielsen}

PulmoTrace ApS, Glamsbjerg, Denmark.

Correspondence: Jørgen G. Nielsen, PulmoTrace ApS, Skovvænget 2, 5620 Glamsbjerg, Denmark. E-mail: jgn@innovision.dk

@ERSpublications

Sulfur hexafluoride multiple-breath washout is insensitive to inspiratory leaks http://ow.ly/Y3o8301KOpY

Cite this article as: Nielsen JG. Impact of leaks in sulfur hexafluoride and nitrogen multiple-breath washout systems. ERJ Open Res 2018; 4: 00119-2018 [https://doi.org/10.1183/23120541.00119-2018]. 
Received: July 232018 | Accepted: Aug 302018

Conflict of interest: J.G. Nielsen is a Chief Medical Officer and indirect owner of the company PulmoTrace ApS that develops, produces and sells devices for measurement of lung clearance index by multiple-breath washout using sulfur hexafluoride.

\section{References}

1 Lenherr N, Ramsey KA, Jost K, et al. Leaks during multiple-breath washout: characterisation and influence on outcomes. ERJ Open Res 2018; 4: 00012-2017.

2 Sullivan L, Forno E, Pedersen K, et al. Nitrogen back-diffusion during multiple-breath washout with 100\% oxygen. Eur Respir J 2017; 50: 1700679.

3 Davies J, Sheridan H, Bell N, et al. Assessment of clinical response to ivacaftor with lung clearance index in cystic fibrosis patients with a G551D-CFTR mutation and preserved spirometry: a randomized controlled trial. Lancet Respir Med 2013; 1: 630-638.

4 Horsley AR, O'Neill K, Downey DG, et al. Closed circuit rebreathing to achieve inert gas wash-in for multiple breath wash-out. ERJ Open Res 2016; 2: 00042-2015. 